\title{
Maternal diet quality before pregnancy and risk of childhood leukaemia
}

\author{
Amanda W. Singer ${ }^{1 *}$, Suzan L. Carmichael ${ }^{2}$, Steve Selvin ${ }^{1}$, Cecilia Fu ${ }^{3}$, Gladys Block ${ }^{1}$ and Catherine Metayer ${ }^{1}$ \\ ${ }^{1}$ Division of Epidemiology, University of California, Berkeley, CA 94720, USA \\ ${ }^{2}$ Department of Pediatrics, Division of Neonatology and Developmental Medicine, Stanford University School of Medicine, \\ Stanford, CA 94305, USA \\ ${ }^{3}$ Children's Hospital of Los Angeles, Los Angeles, CA 90027, USA \\ (Submitted 15 December 2015 - Final revision received 5 August 2016 - Accepted 28 August 2016)
}

\section{Abstract}

Previous studies on maternal nutrition and childhood leukaemia risk have focused on the role of specific nutrients such as folate and have not considered broader measures of diet quality, which may better capture intake of diverse nutrients known to impact fetal development. We examined the relationship between maternal diet quality before pregnancy, as summarised by a diet quality index, and risk of childhood acute lymphoblastic leukaemia (ALL) and acute myeloid leukaemia (AML) in a case-control study in California. Dietary intake in the year before pregnancy was assessed using FFQ in 681 ALL cases, 103 AML cases and 1076 matched controls. Conditional logistic regression was used to estimate OR and $95 \%$ CI for diet quality continuous score and quartiles (Q1-Q4). Higher maternal diet quality score was associated with reduced risk of ALL (OR 0.66; 95\% CI 0.47, 0.93 for Q4 $v$. Q1) and possibly AML (OR 0.42; 95\% CI 0.15, 1.15 for Q4 $v$. Q1). No single index component appeared to account for the association. The association of maternal diet quality with risk of ALL was stronger in children diagnosed under the age of 5 years and in children of women who did not report using vitamin supplements before pregnancy. These findings suggest that the joint effects of many dietary components may be important in influencing childhood leukaemia risk.

Key words: Childhood leukaemia: Diet quality: Prenatal nutrition: Epidemiology

Maternal nutrition during pregnancy may influence the risk of leukaemia in children through its role in fetal development, including the synthesis and repair of DNA, development of epigenetic processes and establishment of the child's immune system. Although most of the studies to date have focused on the relationship between maternal folic acid intake and risk of childhood leukaemia ${ }^{(1)}$, there is evidence that maternal consumption of specific food groups may influence childhood leukaemia risk. Previous studies, including findings from the California Childhood Leukaemia Study (CCLS), which is the basis for this analysis, have suggested that higher maternal consumption of fruits and vegetables may be associated with a reduced risk of childhood acute lymphoblastic leukaemia $(\mathrm{ALL})^{(2-4)}$ and possibly infant leukaemia (i.e. acute leukaemia diagnosed under 1 year of age $)^{(5)}$. Previous studies have also found that other food groups, specifically protein sources such as fish and seafood ${ }^{(3)}$ and beans and beef ${ }^{(2,4)}$, may reduce the risk of ALL. In addition, there is some evidence that maternal consumption of certain foods such as sugars or syrups may increase the risk of $\mathrm{ALL}^{(3,6)}$.

Studies examining maternal diet and childhood leukaemia risk have mostly been limited to specific nutrients ${ }^{(1,7)}$ or specific food components such as processed meats ${ }^{(8)}$, coffee and alcohol ${ }^{(9,10)}$ and dietary inhibitors of the nuclear enzyme topoisomerase $\mathrm{II}^{(5,11,12)}$. Measures of overall diet quality may better represent nutritional status and the complex biological interaction of multiple nutrients ${ }^{(13)}$. High-quality diets characterised by diet quality indices are often positively correlated with biological markers of micronutrient intake and have been associated with reduced risk of all-cause mortality, cancer risk and $\mathrm{CVD}^{(14-18)}$. Maternal dietary patterns and quality have also been associated with birth outcomes such as neural tube and congenital heart defects $^{(19,20)}$. The objective of this study was to examine the association between maternal diet quality, as assessed by a diet quality index, and risk of childhood ALL and acute myeloid leukaemia (AML) in a case-control study in California.

\section{Methods}

\section{Study population}

The CCLS is a case-control study conducted in up to thirty-five counties in the San Francisco Bay Area and the California Central Valley ${ }^{(21)}$. Incident cases of newly diagnosed childhood leukaemia in children aged 0-14 years were ascertained from major paediatric clinical centres from 1995 to 2008. Cases were

Abbreviations: ALL, acute lymphoblastic leukaemia; AML, acute myeloid leukaemia; HEI, healthy eating index.

* Corresponding author: A. W. Singer, fax +1 510643 1735, email amandawsinger@gmail.com 
matched for date of birth, sex, Hispanic ethnicity (based on a parent self-reporting as Hispanic) and maternal race (white, black or other) with controls (ratio 1:1 or 1:2) randomly selected from California birth certificates through the Office of Vital Records at the California Department of Public Health. Control selection procedures and eligibility criteria have been described elsewhere ${ }^{(21,22)}$. Participation of ascertained and eligible cases and controls in the main questionnaire was approximately $86 \%^{(22)}$, and dietary information in the year before pregnancy was provided by $98 \%$ of all respondents (970 cases and 1187 controls). This analysis included ALL and AML case and control participants recruited between 1995 and 2008 whose mothers reported dietary information. This study was conducted in accordance with the Declaration of Helsinki. The University of California, Berkeley Committee for the Protection of Human Subjects, the California Health and Human Services Agency Committee for the Protection of Human Subjects and the Institutional Review Boards of all participating hospitals provided approval for this study. Before interview, written informed consent was obtained from the responding parent of each participating child, and assent was obtained from children aged 7 years and older.

\section{Data collection}

Data were collected by in-person interviews in either English or Spanish and from birth certificates. Details on dietary data collection have been described elsewhere ${ }^{(2,4)}$. In brief, a modified version of the Block FFQ was administered during an in-person interview with the biological mother to assess her dietary intake and vitamin supplement use during the 12 months before the index pregnancy. Macronutrient and micronutrient estimates from the original Block FFQ and various adaptations have been validated in many populations, including men and women of diverse racial groups and ages ${ }^{(23-25)}$. We assessed dietary intake in the year before pregnancy in order to examine nutritional adequacy at the time of conception and early pregnancy. The FFQ contained seventy-six food items and questions on vitamin supplement use before pregnancy. Food items were selected for inclusion in the FFQ by analysing data from the third National Health and Nutrition Examination Survey (NHANES III) and the Hispanic Health and Nutrition Examination Survey to identify foods that were the top population contributors of each nutrient among white, African-American and Hispanic populations. The FFQ also included five questions about whether the mother consumed more, the same amount, or less fruits, vegetables, tofu or soya, tea and water during the pregnancy with the child. Spanish-speaking respondents were administered a Spanish version of the FFQ by bilingual interviewers. The Spanish FFQ included seven additional items common in the diets of the Latino population: evaporated or condensed milk, cooked green peppers, avocado or guacamole, chile peppers or chile sauce, sauces such as mole or sofrito, corn tortillas and flour tortillas. Frequency of consumption of food groups was calculated by summing the reported frequency for all foods in a given food group; component foods of the food groups are reported elsewhere ${ }^{(4)}$. Blocksys and NutritionQuest computer programmes (NutritionQuest) were used to calculate dietary nutrients from food by multiplying frequency of consumption of each food by its nutrient content and reported portion size, and then summing over all foods. Dietary folate intake, calculated in units of dietary folate equivalents ${ }^{(26)}$, accounted for the different amounts of folic acid in food before and after US national fortification of grain products with folic acid in 1998. Nutrients obtained from vitamin supplements were estimated by multiplying the frequency of consumption of each type of supplement (multiple vitamins and specific single vitamins) with the amount of the nutrient in standard compositions of each type.

\section{Diet quality index}

Food frequency data were used to calculate scores for a modified version of the 2010 healthy eating index (HEI-2010). The HEI-2010 is a measure of diet quality that assesses conformance to federal dietary guidance and was updated in 2010 to reflect the 2010 Dietary Guidelines for Americans, the basis for all US government nutrition recommendations and policies $^{(27)}$. The HEI-2010 is considered an appropriate measure of diet quality for women who are pregnant or lactating ${ }^{(27)}$. The HEI-2010 comprises twelve nutritional components: nine 'adequacy' components (total fruit, whole fruit (excluding fruit juice), total vegetables, greens and beans, whole grains, dairy products, total protein foods, seafood and plant proteins, fatty acids) and three 'moderation' components (refined grains, $\mathrm{Na}$, empty calories) ${ }^{(27)}$. We did not have access to the raw data to permit computation of all HEI-2010 components; consequently, the index used in these analyses does not include separate components for whole fruit and seafood and plant proteins, although foods in these categories are incorporated into other components. As we could not distinguish between whole and refined grains in our data, these components were excluded. In addition, our modified index uses dietary fibre from beans for the greens and beans category, and uses percentage of energy content from sweets and grams of dietary trans-fat per day to represent empty calories. We added Fe and folate from food as components because of their inclusion in dietary quality indices for pregnancy ${ }^{(28,29)}$ and because of previous studies indicating that higher maternal $\mathrm{Fe}$ and folate intake is associated with reduced risk of $\mathrm{ALL}^{(7,30-32)}$. Given that the CCLS data were based on a semi-quantitative FFQ, components were scored by quartiles (based on the distribution in controls) instead of at the level of the nutritional standard: for adequacy components, 0 points were assigned to those in the lowest quartile of intake for a given food group or nutrient; 1, 2 and 3 points were assigned to those in the second, third and fourth quartiles of intake, respectively; and vice versa for moderation components (i.e. Na, trans-fat and percentage of energy content from sweets), for which participants in the lowest quartile of intake received the maximum score of 3 points ${ }^{(20)}$. All components except for the fatty acids ratio and percentage of energy content from sweets were scored on a density basis (i.e. per $4184 \mathrm{~kJ}$ $(1000 \mathrm{kcal}))$ to account for the diverse energy consumption of the respondents. All component scores were summed to obtain a total diet quality score with a possible range of 0 (worst) to 33 (best). 


\section{Statistical analysis}

After excluding mothers of cases and controls with Down's syndrome ( $n$ 36), because of the distinct genetic risk of leukaemia among these children, and excluding respondents reporting daily energy consumption of $<2092$ or $>25104 \mathrm{~kJ}$ ( $<500$ or $>6000 \mathrm{cal}$ ) ( $n$ 21), 681 ALL cases and 931 matched ALL controls and 103 AML cases and 145 matched AML controls were available for the analysis. The associations between diet quality score and select covariates were examined through $t$ tests and ANOVA among controls. Pearson's correlation coefficients were calculated to examine the relationship between index components and overall diet quality score among controls. Conditional logistic regression was used to estimate OR and $95 \%$ CI for the association of ALL and AML with diet quality score, as well as the association with each of the index components. We also examined the association of ALL with greater fruit consumption (yes/no), greater vegetable consumption (yes/no) and greater soya consumption (yes/no) during pregnancy (relative to before pregnancy), and we assessed whether or not adding these variables to the diet quality score model substantially changed the OR (>10\%). Separate analyses were conducted for ALL and AML. Diet quality score was examined as both a continuous variable and in quartiles. Models were adjusted for the following covariates, which were selected a priori on the basis of known or hypothesised associations with maternal diet and childhood leukaemia: mother's Hispanic ethnicity, annual household income, father's education, mother's education, maternal age category and vitamin supplement use in the year before pregnancy. Maternal BMI before pregnancy was not included as a covariate because there was a substantial number of missing values $(26 \cdot 1 \%)$ and because it did not change the point estimate or improve the accuracy of the model for diet quality and ALL, as assessed through likelihood ratio tests (data not shown); its influence on the model for AML was not evaluated because of the large reduction in sample size due to missing values. As most women in our study reported modifying their alcohol consumption during pregnancy, with $94.6 \%$ of the respondents indicating they drank much less or no alcohol at all during pregnancy, we did not consider alcohol consumption to be a likely confounder. Similarly, a small percentage of women reported smoking during the 3 months before pregnancy $(12.0 \%)$ or during pregnancy $(8.1 \%)$. As many studies have found that maternal smoking is not associated with an increased risk of childhood leukaemia ${ }^{(10,33-35)}$, we did not consider maternal smoking to be a confounder.

The potential modifying influence of maternal Hispanic ethnicity (Hispanic $v$. non-Hispanic white or other), maternal vitamin supplement use (yes/no) and child's age at diagnosis ( $<$ or $\geq 5$ years) on the association between diet quality score and ALL was assessed through the addition of interaction terms to the statistical models; interaction terms with a $P$ value $<0 \cdot 2$ were considered a statistically significant indication of lack of additivity. We also stratified results for ALL by vitamin supplement use. Models for AML had an insufficient sample size for stratification or test of interaction. All results were considered statistically significant if the $95 \%$ CI excluded $1 \cdot 0$. Statistical analyses were carried out using STATA version 12.
Results

Compared with ALL cases, controls had parents with higher household income and education, and mothers were older at the time of the child's birth and more likely to report vitamin supplement use in the year before pregnancy (Table 1). Controls matched to AML cases had parents with higher household income, and mothers were older at the time of the index child's birth. Among controls, the proportion of women meeting the minimum recommended number of servings of vegetables ( $\geq 3$ servings) and fruits ( $\geq 2$ servings) per day according to the US Department of Agriculture Food Guide Pyramid $^{(36)}$ was 39.6 and $19.6 \%$, respectively. The proportion of women consuming the recommended Food Guide Pyramid servings per day for a given food group was $46.4 \%$ for meat (two to three servings), $31.0 \%$ for dairy products (two to three servings) and $31.7 \%$ for grains (six to eleven servings). However, these results should be interpreted with caution, given that FFQ are more suited to ranking intakes than providing estimates of absolute intakes for entire food groups or nutrients.

Among all cases and controls, diet quality scores ranged from 2 to 30. The mean score was $15 \cdot 6$ (SD 5.1) and 16.5 (SD 5.2) among cases and controls, respectively. The 25 th, 50th and 75 th percentiles were 12, 16 and 19 among cases and 13,16 and 20 among controls, respectively. Among controls, the mean diet quality score was significantly higher in mothers who did not smoke during the 3 months before pregnancy $(P<0 \cdot 001)$, who used vitamin supplements during the year before pregnancy $(P<0.001)$ and who were older at the time of the index pregnancy $(P<0 \cdot 001)$. The mean diet quality score was not significantly different in obese $v$. non-obese controls $(16 \cdot 2 v \cdot 16 \cdot 8$, respectively, $P=0 \cdot 35$ ). Hispanic women had a higher mean diet quality score than non-Hispanic white women or women of other races/ethnicities $(P<0 \cdot 001)$. Consequently, the mean diet quality score among controls was the highest in the lowest education group, comprised of $98 \%$ Hispanic women, followed by the highest education group ( $65 \%$ non-Hispanic white, $12 \%$ Hispanic and $23 \%$ non-Hispanic other race/ethnicity). Correlations of diet quality score with the index components ranged from -0.70 to 0.64 among controls and were in the expected directions, with adequacy components positively correlated and moderation components negatively correlated with overall diet quality score, respectively (Table 2).

Higher maternal diet quality score was associated with a reduced risk of childhood ALL (OR 0.88; $95 \%$ CI 0.78, 0.98 for each five-point increase) (Table 3 ). When examined by quartiles, the reduction in risk was most pronounced among those in the highest quartile of diet quality score (OR 0.66; 95\% CI 0.47, 0.93 for highest $v$. lowest quartile). Maternal Hispanic ethnicity did not modify these associations ( $P=0.62_{\text {for interaction term }}$ ). Although interaction by vitamin supplement use was not statistically significant $(P=0.65)$, the reduction in ALL risk associated with higher diet quality score was greater among non-users of vitamin supplements (Table 4). There was a negative association of diet quality score with ALL among children younger than 5 years at diagnosis (OR 0.79; $95 \% \mathrm{CI}$ $0.68,0.92$ for a five-point increase in diet quality score among 382 cases and 503 controls) and no association among children 
Table 1. Select characteristics of matched case and control children, by leukaemia subtype: the California Childhood Leukemia Study* (Numbers and percentages; mean values and standard deviations)

\begin{tabular}{|c|c|c|c|c|c|c|c|c|}
\hline & \multicolumn{4}{|c|}{ ALL } & \multicolumn{4}{|c|}{ AML } \\
\hline & \multicolumn{2}{|c|}{ Cases } & \multicolumn{2}{|c|}{ Controls } & \multicolumn{2}{|c|}{ Cases } & \multicolumn{2}{|c|}{ Controls } \\
\hline & $n$ & $\%$ & $n$ & $\%$ & $n$ & $\%$ & $n$ & $\%$ \\
\hline Total & 681 & & 931 & & 103 & & 145 & \\
\hline \multicolumn{9}{|l|}{ Child's sex } \\
\hline Male & 390 & $57 \cdot 27$ & 538 & 57.79 & 56 & $54 \cdot 37$ & 80 & $55 \cdot 17$ \\
\hline Female & 291 & $42 \cdot 73$ & 393 & $42 \cdot 21$ & 47 & 45.63 & 65 & 44.83 \\
\hline \multicolumn{9}{|c|}{ Child's age at diagnosis/reference date (years) } \\
\hline$<2$ & 83 & $12 \cdot 19$ & 106 & 11.39 & 28 & $27 \cdot 18$ & 44 & $30 \cdot 34$ \\
\hline $2-6$ & 396 & $58 \cdot 15$ & 543 & 58.32 & 19 & 18.45 & 28 & $19 \cdot 31$ \\
\hline $6-9$ & 96 & $14 \cdot 10$ & 132 & $14 \cdot 18$ & 15 & 14.56 & 19 & $13 \cdot 10$ \\
\hline$\geq 9$ & 106 & $15 \cdot 57$ & 150 & $16 \cdot 11$ & 41 & 39.81 & 54 & $37 \cdot 24$ \\
\hline \multicolumn{9}{|l|}{ Child's ethnicity } \\
\hline Hispanic & 312 & $45 \cdot 81$ & 414 & 44.47 & 40 & 38.83 & 56 & 38.62 \\
\hline Non-Hispanic white & 256 & 37.59 & 365 & 39.21 & 44 & $42 \cdot 72$ & 62 & $42 \cdot 76$ \\
\hline Non-Hispanic other & 112 & $16 \cdot 45$ & 152 & $16 \cdot 33$ & 19 & $18 \cdot 45$ & 27 & 18.62 \\
\hline Missing & 1 & 0.15 & 0 & 0.00 & 0 & 0.00 & 0 & 0.00 \\
\hline \multicolumn{9}{|l|}{ Mother's race/ethnicity } \\
\hline Hispanic & 285 & 41.85 & 364 & 39.10 & 35 & 33.98 & 50 & 34.48 \\
\hline Non-Hispanic white & 298 & $43 \cdot 76$ & 437 & 46.94 & 55 & 53.40 & 75 & $51 \cdot 72$ \\
\hline Non-Hispanic other & 98 & 14.39 & 130 & 13.96 & 13 & 12.62 & 20 & 13.79 \\
\hline \multicolumn{9}{|c|}{ Household annual income (USD)† } \\
\hline$<15000$ & 105 & $15 \cdot 42$ & 93 & 9.99 & 21 & 20.39 & 12 & $8 \cdot 28$ \\
\hline $15000-29999$ & 119 & $17 \cdot 47$ & 116 & 12.46 & 20 & $19 \cdot 42$ & 22 & $15 \cdot 17$ \\
\hline $30000-44999$ & 106 & 15.57 & 116 & $12 \cdot 46$ & 13 & $12 \cdot 62$ & 15 & $10 \cdot 34$ \\
\hline $45000-59999$ & 104 & $15 \cdot 27$ & 126 & 13.53 & 9 & $8 \cdot 74$ & 20 & $13 \cdot 79$ \\
\hline $60000-74999$ & 51 & 7.49 & 103 & 11.06 & 11 & $10 \cdot 68$ & 14 & 9.66 \\
\hline $75000+$ & 196 & $28 \cdot 78$ & 377 & 40.49 & 29 & $28 \cdot 16$ & 62 & $42 \cdot 76$ \\
\hline \multicolumn{9}{|l|}{ Mother's education } \\
\hline None or elementary & 84 & $12 \cdot 33$ & 71 & 7.63 & 12 & 11.65 & 14 & 9.66 \\
\hline High school or similar & 211 & 30.98 & 251 & 29.96 & 34 & 33.01 & 38 & $26 \cdot 21$ \\
\hline Some college or similar & 188 & $27 \cdot 61$ & 293 & 31.47 & 24 & $23 \cdot 30$ & 38 & $26 \cdot 21$ \\
\hline Bachelor's degree or higher & 198 & 29.07 & 316 & 33.94 & 33 & 32.04 & 55 & 37.93 \\
\hline \multicolumn{9}{|l|}{ Father's education } \\
\hline None or elementary & 78 & 11.45 & 99 & 10.63 & 13 & $12 \cdot 62$ & 14 & 9.66 \\
\hline High school or similar & 238 & 34.95 & 271 & 29.11 & 36 & 34.95 & 44 & $30 \cdot 34$ \\
\hline Some college or similar & 137 & $20 \cdot 12$ & 231 & 24.81 & 17 & $16 \cdot 50$ & 35 & $24 \cdot 14$ \\
\hline Bachelor's degree or higher & 207 & $30 \cdot 40$ & 295 & 31.69 & 34 & 33.01 & 49 & 33.79 \\
\hline Missing & 21 & 3.08 & 35 & 3.76 & 3 & $2 \cdot 91$ & 3 & 2.07 \\
\hline \multicolumn{9}{|c|}{ Maternal age at child's birth (years) } \\
\hline$<25$ & 231 & 33.92 & 237 & 25.46 & 34 & 33.01 & 25 & $17 \cdot 24$ \\
\hline $25-35$ & 342 & $50 \cdot 22$ & 516 & 55.42 & 55 & 53.40 & 89 & $61 \cdot 38$ \\
\hline$>35$ & 108 & $15 \cdot 86$ & 178 & $19 \cdot 12$ & 14 & 13.59 & 31 & $21 \cdot 38$ \\
\hline \multicolumn{9}{|c|}{ Vitamin supplement use in year before pregnancył } \\
\hline Yes & 213 & 31.28 & 347 & $37 \cdot 27$ & 34 & 33.01 & 56 & 38.62 \\
\hline No & 463 & 67.99 & 579 & $62 \cdot 19$ & 68 & 66.02 & 88 & $60 \cdot 69$ \\
\hline Missing & 5 & 0.73 & 5 & 0.54 & 1 & 0.97 & 1 & 0.69 \\
\hline \multicolumn{9}{|l|}{ Healthy eating index score } \\
\hline Mean & \multicolumn{2}{|c|}{$15 \cdot 7$} & \multicolumn{2}{|c|}{$16 \cdot 5$} & \multicolumn{2}{|c|}{$15 \cdot 6$} & \multicolumn{2}{|c|}{$16 \cdot 5$} \\
\hline SD & & & & & & & & \\
\hline
\end{tabular}

ALL, acute lymphoblastic leukaemia; AML, acute myeloid leukaemia; USD, US dollars.

* Cases and controls were matched 1:1 or 1:2 on date of birth, sex, Hispanic ethnicity (based on a parent self-reporting as Hispanic) and maternal race (white, black or other). ALL cases and controls differed by income $(P<0.01)$, mother's education $(P<0.01)$, father's education $(P=0.04)$, maternal age $(P<0.01)$ and vitamin supplement use in the year before pregnancy $(P=0.01)$. AML cases and controls differed by income $(P=0.03)$ and maternal age $(P=0.01)$.

$\dagger$ Missing values for income ( $n$ 58) were assigned to the median income level (45000-59999 USD).

$\ddagger$ Any use of single or multiple vitamins.

diagnosed at 5 years of age or older (OR 1.02; $95 \%$ CI 0.84, 1.24 for a five-point increase among 256 cases and 340 controls;

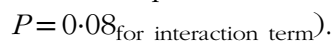

The negative association of higher maternal diet quality score with risk of AML was of similar magnitude to that observed for ALL, although the $95 \%$ CI included one (OR 0.76; $95 \%$ CI 0.52, 1.11) (Table 3). There was a similar trend of decreasing AML risk with higher diet quality score when examined by quartiles (OR 0.42; 95\% CI 0.15, 1.15 for highest $v$. lowest quartile).

When components of the diet quality index were examined separately, a reduction in risk of ALL and AML was observed for higher maternal consumption of fruits (Table 5). Other index components were not associated with ALL or AML. Because of the strong association between daily fruit servings and ALL and 
Table 2. Descriptive information about the components of the modified healthy eating index (HEI) 2010 among controls (Medians and 25th-75th percentiles)

\begin{tabular}{|c|c|c|c|c|}
\hline Modified HEI-2010 components & $\begin{array}{c}\text { Criterion for } \\
\text { maximum score of } 3\end{array}$ & Median & $\begin{array}{l}\text { 25th-75th } \\
\text { percentiles }\end{array}$ & $\begin{array}{l}\text { Correlation with } \\
\text { score among controls* }\end{array}$ \\
\hline \multicolumn{5}{|l|}{ Adequacy } \\
\hline Fruits (daily servings/4184 kJ (1000 kcal)) & Highest quartile & 0.5 & $0.3-0.8$ & 0.53 \\
\hline Vegetables (daily servings $/ 4184 \mathrm{~kJ}(1000 \mathrm{kcal}))$ & Highest quartile & $1 \cdot 2$ & $0.8-1.9$ & 0.40 \\
\hline Dietary fibre from beans $(\mathrm{g} / 4184 \mathrm{~kJ}(1000 \mathrm{kcal}))$ & Highest quartile & $1 \cdot 1$ & $0.6-2 \cdot 2$ & 0.39 \\
\hline Dairy products (serving/4184 kJ (1000 kcal)) & Highest quartile & 0.9 & $0.5-1.3$ & $0 \cdot 19$ \\
\hline Total protein foods (g/4184 kJ (1000 kcal)) & Highest quartile & 39.7 & $34 \cdot 6-45 \cdot 0$ & 0.34 \\
\hline Fatty acids ((PUFA + MUFA)/SFA) & Highest quartile & 1.8 & $1 \cdot 6-2 \cdot 1$ & 0.28 \\
\hline Dietary Fe (mg/4184 kJ (1000 kcal)) & Highest quartile & $7 \cdot 1$ & $6.1-8.4$ & 0.46 \\
\hline Dietary folate (DFE/4184 kJ (1000 kcal)) & Highest quartile & $226 \cdot 2$ & $165 \cdot 7-289.7$ & 0.64 \\
\hline \multicolumn{5}{|l|}{ Moderation } \\
\hline $\mathrm{Na}(\mathrm{g} / 4184 \mathrm{~kJ}(1000 \mathrm{kcal}))$ & Lowest quartile & $1 \cdot 2$ & $1 \cdot 1-1 \cdot 3$ & -0.06 \\
\hline Trans-fat $(\mathrm{g} / 4184 \mathrm{~kJ}(1000 \mathrm{kcal}))$ & Lowest quartile & $3 \cdot 3$ & $2 \cdot 4-4.3$ & -0.70 \\
\hline Percentage of energy content from sweets & Lowest quartile & $7 \cdot 3$ & $4 \cdot 0-13 \cdot 0$ & -0.59 \\
\hline
\end{tabular}

DFE, dietary folate equivalents.

* The correlations of each index component with the overall HEI score among controls were in the expected directions (i.e. adequacy components were positively correlated with the HEI score, and moderation components were negatively correlated with the HEI score).

Table 3. Association between modified healthy eating index (HEI) 2010 and risk of childhood acute lymphoblastic leukaemia (ALL) and acute myeloid leukaemia (AML), overall and by child's age at diagnosis/ reference date*

(Odds ratios and $95 \%$ confidence intervals)

\begin{tabular}{|c|c|c|c|c|}
\hline \multirow[b]{2}{*}{ Modified HEI-2010 } & \multicolumn{2}{|c|}{$\begin{array}{l}\text { ALL ( } 638 \text { cases, } \\
843 \text { controls) }\end{array}$} & \multicolumn{2}{|c|}{$\begin{array}{c}\text { AML (96 cases, } \\
125 \text { controls) }\end{array}$} \\
\hline & OR & $95 \% \mathrm{Cl}$ & OR & $95 \% \mathrm{Cl}$ \\
\hline $\begin{array}{r}\text { Continuous score } \dagger \\
\text { Quartile } 1(<13)\end{array}$ & 0.88 & $\begin{array}{l}0.78,0.98 \\
\text { ef. }\end{array}$ & $0 \cdot 76$ & $\begin{array}{l}0.52,1.11 \\
\text { Ref. }\end{array}$ \\
\hline Quartile 2 (13-15) & 0.71 & $0.51,1.00$ & 0.65 & $0.25,1.69$ \\
\hline Quartile 3 (16-19) & 0.73 & $0.54,1.01$ & 0.60 & $0.21,1.68$ \\
\hline Quartile 4 (>20) & 0.66 & $0.47,0.93$ & 0.42 & $0.15,1 \cdot 15$ \\
\hline Age $<5$ years & \multicolumn{2}{|c|}{382 cases, 503 controls } & & \\
\hline Continuous score $†$ & 0.79 & $0.68,0.92$ & & - \\
\hline Age $\geq 5$ years & \multicolumn{2}{|c|}{256 cases, 340 controls } & & \\
\hline Continuous score $†$ & 1.02 & $0.84,1.24$ & & - \\
\hline
\end{tabular}

Ref., referent values.

* Models adjusted for mother's Hispanic ethnicity, father's education, mother's education, household income, maternal age at child's birth and vitamin supplement use before pregnancy. The categorisation of diet quality score by quartiles was based on the distribution in controls.

† OR for a five-point increase in the HEI-2010 score.

AML, we calculated a limited diet quality score without fruit consumption as a component and found that its associations with ALL and AML did not substantially change (i.e. OR 0.89; $95 \%$ CI $0.79,1.01$ and OR 0.79; $95 \%$ CI 0.53, 1.17, respectively, for a five-unit change in score). The moderate correlation between fruit consumption and the limited score $(r \quad 0.37)$ suggests that the association of overall diet quality score with ALL and AML may not be entirely due to the influence of the fruit component.

Children of women who reported consuming much more or somewhat more vegetables during pregnancy had a reduced risk of ALL (OR 0.70; 95\% CI 0.56, 0.89 among 593 cases and 774 controls), as did children of women who reported consuming much more or somewhat more fruits during pregnancy, although the CI included 1.0 (OR 0.87; 95\% CI 0.69, 1.09 among 622 cases and 819 controls). There was no statistically significant
Table 4. Association between modified healthy eating index (HEI) 2010 and risk of childhood acute lymphoblastic leukaemia among vitamin supplement users and non-users before pregnancy* (Odds ratios and $95 \%$ confidence intervals)

\begin{tabular}{|c|c|c|c|c|}
\hline \multirow[b]{2}{*}{ Modified HEI-2010 } & \multicolumn{2}{|c|}{$\begin{array}{l}\text { Vitamin supplement } \\
\text { users (109 cases, } \\
130 \text { controls } \dagger)\end{array}$} & \multicolumn{2}{|c|}{$\begin{array}{c}\text { Vitamin supplement } \\
\text { non-users ( } 321 \text { cases, } \\
371 \text { controls } \dagger)\end{array}$} \\
\hline & OR & $95 \% \mathrm{Cl}$ & OR & $95 \% \mathrm{Cl}$ \\
\hline Continuous score & 1.00 & $0.74,1.36$ & 0.76 & $0.63,0.92$ \\
\hline Quartile $1(<13)$ & & Ref. & & Ref. \\
\hline Quartile 2 (13-15) & 0.83 & $0.34,2 \cdot 01$ & 0.63 & $0.37,1.06$ \\
\hline Quartile $3(16-19)$ & 0.74 & $0.30,1.83$ & 0.52 & $0.32,0.86$ \\
\hline Quartile 4 (>20) & 1.03 & $0.41,2.57$ & 0.43 & $0.25,0.76$ \\
\hline
\end{tabular}

Ref., referent values.

* Models adjusted for mother's Hispanic ethnicity, father's education, mother's education, household income and maternal age at child's birth. The categorisation of diet quality score by quartiles was based on the distribution in controls.

$\dagger$ By stratifying the conditional logistic regression analyses on a non-matching variable, case-control matched sets discordant on vitamin supplement use were excluded from analyses.

‡ OR for a five-point increase in the HEl-2010 score.

association of greater soya consumption during pregnancy with risk of ALL (OR 1.21; $95 \%$ CI 0.76, 1.93). Adding more fruit, more vegetable or more soya consumption during pregnancy to the diet quality score model as a covariate did not substantially change the OR for diet quality score (data not shown).

\section{Discussion}

Our data suggest a reduction in the risk of ALL with higher maternal diet quality. The association of AML with higher maternal diet quality was of similar magnitude to the association observed for ALL, although this finding did not reach statistical significance. No single food group or nutrient that was part of the diet quality score appeared to be driving the results, suggesting that the quality of the whole diet and the cumulative effects of many dietary components may be important in 
Table 5. Associations between individual components of the modified healthy eating index (HEI) 2010 and risk of childhood acute lymphoblastic leukaemia (ALL) and acute myeloid leukaemia (AML)*

(Odds ratios and $95 \%$ confidence intervals)

\begin{tabular}{|c|c|c|c|c|}
\hline & \multicolumn{2}{|c|}{ ALL (638 cases, 843 controls) } & \multicolumn{2}{|c|}{ AML (96 cases, 125 controls) } \\
\hline & OR & $95 \% \mathrm{Cl}$ & OR & $95 \% \mathrm{Cl}$ \\
\hline \multicolumn{5}{|l|}{ Adequacy components } \\
\hline Fruits $(1$ serving $/ 4184 \mathrm{~kJ}(1000 \mathrm{kcal}))$ & 0.70 & $0.52,0.94$ & 0.23 & $0.08,0.70$ \\
\hline Vegetables (1 serving/4184 kJ (1000 kcal)) & 0.97 & $0.86,1.10$ & 0.84 & $0.54,1.30$ \\
\hline Dairy products ( 1 serving/4184 kJ (1000 kcal)) & 1.01 & $0.84,1.22$ & 0.87 & $0.48,1.57$ \\
\hline Dietary fibre from beans ( $1 \mathrm{~g} / 4184 \mathrm{~kJ}(1000 \mathrm{kcal}))$ & 0.95 & $0.88,1.02$ & 1.03 & $0.80,1.34$ \\
\hline Protein $(10 \mathrm{~g} / 4184 \mathrm{~kJ}(1000 \mathrm{kcal}))$ & 0.91 & $0.79,1.05$ & 1.00 & $0.63,1.59$ \\
\hline Fatty acid ratio & 1.07 & $0.78,1.45$ & 1.08 & $0.42,2.77$ \\
\hline Dietary Fe (1 mg/4184 kJ (1000 kcal)) & 0.98 & $0.93,1.03$ & 0.87 & $0.73,1.03$ \\
\hline Dietary folate $(100 \mathrm{DFE} / 4184 \mathrm{~kJ}(1000 \mathrm{kcal}))$ & 0.97 & $0.83,1.12$ & 0.83 & $0.56,1.21$ \\
\hline \multicolumn{5}{|l|}{ Moderation components } \\
\hline $\mathrm{Na}(100 \mathrm{mg} / 4184 \mathrm{~kJ}(1000 \mathrm{kcal}))$ & 1.05 & $0.99,1.11$ & 0.99 & $0.85,1.17$ \\
\hline Trans-fat $(1 \mathrm{~g} / 4184 \mathrm{~kJ}(1000 \mathrm{kcal}))$ & 1.07 & $0.99,1.16$ & $1 \cdot 11$ & $0.85,1.44$ \\
\hline Percentage of energy content from sweets $(10 \%)$ & 1.09 & $0.94,1.26$ & 1.40 & $0.84,2.34$ \\
\hline
\end{tabular}

DFE, dietary folate equivalents.

* Separate models for each energy-adjusted food group/nutrient as continuous variables adjusted for maternal Hispanic ethnicity, household income, mother's education, father's education, maternal age category and vitamin supplement use. Fatty acid ratio and percentage of energy content from sweets were not energy adjusted.

influencing childhood leukaemia risk. To our knowledge, this is the first study to examine maternal diet quality in relation to childhood leukaemia. However, our findings are consistent with previous studies, indicating that higher maternal consumption of fruits and vegetables and higher intake of micronutrients such as folic acid may be associated with a reduced risk of childhood $\mathrm{ALL}^{(1-4)}$

Although much attention has been focused on the role of folate in children's health outcomes, there is increasing evidence of the importance of other micronutrients for prenatal development and birth outcomes, such as Fe, vitamin D and $\mathrm{I}^{(37,38)}$. A measure of diet quality may provide a holistic representation of maternal diet, as diet quality index scores are positively associated with a wide range of beneficial nutrients (e.g. antioxidants, carotenoids) and negatively associated with intake of potentially harmful dietary components (e.g. SFA $)^{(14)}$. Previous studies have found that the HEI score is strongly correlated with biomarkers of several micronutrients important for maternal and child health, including folate, vitamins $\mathrm{C}$ and $\mathrm{E}$, and carotenoids ${ }^{(15,39)}$.

Maternal diet quality may influence leukaemia risk in children through the influence of specific nutrients such as folic acid or other methyl donors on DNA synthesis and repair or epigenetic processes $^{(40,41)}$. An alternative or complementary pathway by which maternal nutrition may influence childhood leukaemia risk is through its impact on the development of the child's immune system both before and after birth. Immune system development begins early in gestation, with a possible period of heightened vulnerability in immune cell development thought to occur when tissues are being seeded by precursors of immune cells (i.e. 4-7 weeks for myeloid-derived cells and 8-18 weeks for lymphoid cells) ${ }^{(42)}$. There are at least three hypothesised pathways by which maternal malnutrition may influence the development of the fetal immune system: (1) maternal malnutrition may be a stressor, resulting in a high concentration of maternal cortisol previously shown to influence the developing fetal immune system; (2) low levels of micronutrients may interfere with organogenesis and the normal proliferation of immune cells; and (3) poor maternal nutrition could alter the quality and quantity of immune factors transferred prenatally through the placenta or postnatally through the mammary gland ${ }^{(42,43)}$.

There is also interest in the role of infant birth weight in childhood leukaemia risk. Numerous studies have found an increased risk of ALL and AML with higher birth weight or among children who were large for gestational age ${ }^{(44-49)}$. A recent metaanalysis of twelve case-control studies from the Childhood Leukemia International Consortium reported a statistically significant increased risk of ALL in children who were large for gestational age relative to appropriate for gestational age (OR $1 \cdot 24 ; 95 \%$ CI 1.13, 1.36) among 7348 cases and 12489 controls $^{(50)}$. Although birth weight is known to be affected by a variety of factors ${ }^{(51-53)}$, certain dietary aspects such as the glycaemic load of the diet during pregnancy ${ }^{(54)}$ and maternal intake of one-carbon metabolism nutrients ${ }^{(55-58)}$ may play a role in fetal growth and birth weight. However, we did not find a difference in maternal diet quality among women who had children with high birth weight (i.e. $\geq 4500 \mathrm{~g}$ ) and women who did not (data not shown). In addition, maternal diet quality was not associated with maternal BMI. Thus, our data do not suggest that maternal obesity or infant birth weight is the mechanism by which maternal diet quality influences childhood leukaemia risk.

Further understanding of the biological mechanisms by which maternal diet quality may influence childhood leukaemia risk is needed. We found that there was only an association of maternal diet quality with risk of ALL among children diagnosed under 5 years of age, which strengthens the inference that maternal nutritional status may influence the developmental processes occurring in utero that are related to the initiation of leukaemia before birth ${ }^{(59,60)}$. Furthermore, increased vegetable and possibly fruit consumption during pregnancy was associated with a reduced risk of ALL even after controlling for 
pre-pregnancy diet quality, suggesting that both maternal nutrition around the time of conception and throughout pregnancy may influence the risk of childhood leukaemia. This finding is consistent with previous studies, which found that the associations between maternal vitamin supplement use and childhood leukaemia did not significantly differ by period of supplementation (i.e. preconception, during pregnancy and by trimester) $^{(1)}$.

We used a measure of diet quality defined a priori on the basis of a validated index that measures conformance with federal dietary guidelines ${ }^{(61)}$. Our index was limited in that it excluded some HEI-2010 components such as whole and refined grains and was unable to examine the role of other components of interest in fetal development, such as seafood and plant proteins. However, there was substantial overlap in our index with the HEI-2010 and other diet quality indices. Although we were unable to validate our modified index, the construct validity of this index was supported by its ability to successfully distinguish between groups with known differences in diet quality (e.g. smokers and non-smokers) ${ }^{(61)}$. In our index, each component received the same weight, which we believe is appropriate given the limited evidence on the association between maternal consumption of food groups and risk of childhood leukaemia. Calculation of our score by quartiles produced a smaller range of component scores and overall score than the traditional HEI-2010, but the estimated 5 and 95 percentiles of total score ( 7.5 and 25 , respectively) indicated that there was a wide range of scores among individuals.

Income and education are positively associated with better diet quality among adults ${ }^{(62,63)}$. However, the observation in this study that Hispanic women had higher diet quality scores than women of other ethnicities/races despite having lower income and education levels is consistent with findings from other studies ${ }^{(64)}$. A recent NHANES analysis found that Hispanics have better diet quality than whites or blacks, with greater consumption of fruits, vegetables and legumes ${ }^{(62)}$. In addition, a growing body of research has suggested that the diet quality among Hispanic women in the US declines with increasing levels of acculturation ${ }^{(65-68)}$. The addition of an interaction term to the statistical model did not indicate that there was substantial heterogeneity in the association between maternal diet quality and ALL by maternal Hispanic ethnicity.

The strengths of this study include the population-based selection of controls and the thorough assessment of maternal dietary intake in the year before pregnancy. Potential limitations include measurement errors in the estimation of maternal food and nutrient intakes occurring several years in the past, which may increase the likelihood of null findings or small effect sizes ${ }^{(69,70)}$. Although we were able to assess reported changes in fruit, vegetable and soya consumption during pregnancy, we did not have additional data on dietary exposures during pregnancy, which is a limitation of this study. Data on vitamin supplement use during pregnancy were available for phase III respondents; however, because $94 \%$ of women reported use of vitamin supplements during pregnancy, the limited variability in this potential covariate precluded informative analyses. Although recall bias is possible, many of the validation studies examining the extent of maternal recall bias in case-control studies of child birth outcomes have found no systematic differences in recall according to case-control status ${ }^{(71-78)}$, and research suggests that recall bias generally occurs under specific circumstances such as when a putative association has been publicised or is believed to exist by the community under study $^{(79)}$. We believe that recall bias is less likely to occur for a complex exposure such as diet quality, which is based on reported intake of diverse food groups and nutrients calculated from seventy-six food items and has not previously been publicised as being possibly related to leukaemia risk. Furthermore, a maternal diet reliability sub-study in the CCLS ( $n$ 85) found that the reliability of five select FFQ questions did not differ by case-control status (unpublished results). The sociodemographic characteristics and health behaviours of mothers with higher diet quality differ from mothers with low diet quality, and it is possible that we did not adjust for all relevant confounders. However, adjustment for several potential confounders including measures of socio-economic status had little influence on the associations between diet quality score and ALL and AML.

A measure of maternal diet quality attempts to better capture intakes of the myriad nutrients and bioactive components consumed from foods, in contrast to a limited focus on particular nutrients. Given the importance of multiple nutrients and food components during pregnancy and lactation, this representation of maternal diet may be better suited to capture the complex interplay of diverse nutritional factors on fetal development, birth outcomes and child health. Our finding of a strong association between maternal diet quality score and risk of childhood leukaemia suggests that maternal nutritional status during pregnancy may play a role in the development of leukaemia, and that the cumulative effects of many dietary components may be more important than the effect of a single nutrient.

\section{Acknowledgements}

The authors thank the staff of the California Childhood Leukemia Study (CCLS) for their contributions to this study. The authors are grateful to the families who participated in this study and the clinical investigators and their teams at the collaborating hospitals for their role in recruiting patients to this study: University of California, Davis, Medical Center (J. Ducore), University of California, San Francisco (M. Loh and K. Matthay), Children's Hospital of Central California (V. Crouse), Lucile Packard Children's Hospital (G. Dahl), Children's Hospital Oakland (J. Feusner), Kaiser Permanente Roseville (formerly Sacramento; K. Jolly and V. Kiley), Kaiser Permanente Santa Clara (C. Russo, A. Wong and D. Taggar), Kaiser Permanente San Francisco (K. Leung) and Kaiser Permanente Oakland (D. Kronish and S. Month).

This research was supported by National Institute of Environmental Health Sciences grants R01ES009137 and P-42-ES-04705-18 (University of California, Berkeley).

A. W. S. formulated the research question and led the analysis and writing of the paper. S. L. C. and G. B. advised on nutritional epidemiological methods, interpreted the results and critically reviewed the paper. S. S. advised on the statistical 
methods, interpreted the results and critically reviewed the paper. C. F. advised on the interpretation of the results and critically reviewed the paper. C. M. is responsible for the overall design of the CCLS study, provided the dietary data, advised on the analysis, interpreted the results and critically reviewed the paper.

The authors declare that there are no conflicts of interest.

\section{References}

1. Metayer C, Milne E, Dockerty JD, et al. (2014) Maternal supplementation with folic acid and other vitamins and risk of leukemia in offspring: a Childhood Leukemia International Consortium study. Epidemiology 25, 811-822.

2. Jensen CD, Block G, Buffler P, et al. (2004) Maternal dietary risk factors in childhood acute lymphoblastic leukemia (United States). Cancer Causes Control 15, 559-570.

3. Petridou E, Ntouvelis E, Dessypris N, et al. (2005) Maternal diet and acute lymphoblastic leukemia in young children. Cancer Epidemiol Biomarkers Prev 14, 1935-1939.

4. Kwan ML, Jensen CD, Block G, et al. (2009) Maternal diet and risk of childhood acute lymphoblastic leukemia. Public Health Rep 124, 503-514.

5. Spector LG, Xie Y, Robison LL, et al. (2005) Maternal diet and infant leukemia: the DNA topoisomerase II inhibitor hypothesis: a report from the children's oncology group. Cancer Epidemiol Biomarkers Prev 14, 651-655.

6. Bonaventure A, Rudant J, Goujon-Bellec S, et al. (2013) Childhood acute leukemia, maternal beverage intake during pregnancy, and metabolic polymorphisms. Cancer Causes Control 24, 783-793.

7. Kwan ML, Metayer C, Crouse V, et al. (2007) Maternal illness and drug/medication use during the period surrounding pregnancy and risk of childhood leukemia among offspring. Am J Epidemiol 165, 27-35.

8. Peters JM, Preston-Martin S, London SJ, et al. (1994) Processed meats and risk of childhood leukemia (California, USA). Cancer Causes Control 5, 195-202.

9. Milne E, Royle JA, Bennett LC, et al. (2011) Maternal consumption of coffee and tea during pregnancy and risk of childhood ALL: results from an Australian case-control study. Cancer Causes Control 22, 207-218.

10. Menegaux F, Ripert M, Hemon D, et al. (2007) Maternal alcohol and coffee drinking, parental smoking and childhood leukaemia: a French population-based case-control study. Paediatr Perinat Epidemiol 21, 293-299.

11. Ross JA, Potter JD, Reaman GH, et al. (1996) Maternal exposure to potential inhibitors of DNA topoisomerase II and infant leukemia (United States): a report from the Children's Cancer Group. Cancer Causes Control 7, 581-590.

12. Strick R, Strissel PL, Borgers S, et al. (2000) Dietary bioflavonoids induce cleavage in the MLL gene and may contribute to infant leukemia. Proc Natl Acad Sci U S A 97, $4790-4795$.

13. Hu FB (2002) Dietary pattern analysis: a new direction in nutritional epidemiology. Curr Opin Lipidol 13, 3-9.

14. Kant AK (2004) Dietary patterns and health outcomes. J Am Diet Assoc 104, 615-635.

15. Weinstein SJ, Vogt TM \& Gerrior SA (2004) Healthy eating index scores are associated with blood nutrient concentrations in the third National Health and Nutrition Examination Survey. J Am Diet Assoc 104, 576-584
16. Harnack L, Nicodemus K, Jacobs DR Jr, et al. (2002) An evaluation of the dietary guidelines for Americans in relation to cancer occurrence. Am J Clin Nutr 76, 889-896.

17. Schwingshackl L \& Hoffmann G (2015) Diet quality as assessed by the healthy eating index, the alternate healthy eating index, the dietary approaches to stop hypertension score, and health outcomes: a systematic review and meta-analysis of cohort studies. J Acad Nutr Diet 115, 780-800.

18. Reedy J, Krebs-Smith SM, Miller PE, et al. (2014) Higher diet quality is associated with decreased risk of all-cause, cardiovascular disease, and cancer mortality among older adults. Jf Nutr 144, 881-889.

19. Sotres-Alvarez D, Siega-Riz AM, Herring AH, et al. (2013) Maternal dietary patterns are associated with risk of neural tube and congenital heart defects. Am J Epidemiol 177, $1279-1288$

20. Carmichael SL, Yang W, Feldkamp ML, et al. (2012) Reduced risks of neural tube defects and orofacial clefts with higher diet quality. Arch Pediatr Adolesc Med 166, 121-126.

21. Ma X, Buffler PA, Layefsky M, et al. (2004) Control selection strategies in case-control studies of childhood diseases. Am J Epidemiol 159, 915-921.

22. Bartley K, Metayer C, Selvin S, et al. (2010) Diagnostic $\mathrm{X}$-rays and risk of childhood leukaemia. Int J Epidemiol 39, 1628-1637.

23. Block G, Hartman AM \& Naughton D (1990) A reduced dietary questionnaire: development and validation. Epidemiology 1, 58-64.

24. Cade J, Thompson R, Burley V, et al. (2002) Development, validation and utilisation of food-frequency questionnaires a review. Public Health Nutr 5, 567-587.

25. Block G, Woods M, Potosky A, et al. (1990) Validation of a self-administered diet history questionnaire using multiple diet records. J Clin Epidemiol 43, 1327-1335.

26. Suitor CW \& Bailey LB (2000) Dietary folate equivalents: interpretation and application. J Am Diet Assoc 100, 88-94.

27. Guenther PM, Casavale KO, Reedy J, et al. (2013) Update of the healthy eating index: HEI-2010. J Acad Nutr Diet 113, 569-580.

28. Rifas-Shiman SL, Rich-Edwards JW, Kleinman KP, et al. (2009) Dietary quality during pregnancy varies by maternal characteristics in Project Viva: a US cohort. J Am Diet Assoc 109, 1004-1011.

29. Bodnar LM \& Siega-Riz AM (2002) A diet quality index for pregnancy detects variation in diet and differences by sociodemographic factors. Public Health Nutr 5, 801-809.

30. Thompson JR, Gerald PF, Willoughby ML, et al. (2001) Maternal folate supplementation in pregnancy and protection against acute lymphoblastic leukaemia in childhood: a case-control study. Lancet 358, 1935-1940.

31. Wen W, Shu XO, Potter JD, et al. (2002) Parental medication use and risk of childhood acute lymphoblastic leukemia. Cancer 95, 1786-1794.

32. Bailey HD, Miller M, Langridge A, et al. (2012) Maternal dietary intake of folate and vitamins $B_{6}$ and $B_{12}$ during pregnancy and the risk of childhood acute lymphoblastic leukemia. Nutr Cancer 64, 1122-1130.

33. Chang JS (2009) Parental smoking and childhood leukemia. Methods Mol Biol 472, 103-137.

34. Pershagen G, Ericson A \& Otterblad-Olausson P (1992) Maternal smoking in pregnancy: does it increase the risk of childhood cancer? Int J Epidemiol 21, 1-5.

35. Mucci LA, Granath F \& Cnattingius S (2004) Maternal smoking and childhood leukemia and lymphoma risk among 1,440,542 Swedish children. Cancer Epidemiol Biomarkers Prev 13, $1528-1533$ 
36. United States Department of Agriculture (1996) The Food Guide Pyramid. Washington, DC: USDA Center for Nutrition Policy and Promotion.

37. Allen LH (2005) Multiple micronutrients in pregnancy and lactation: an overview. Am J Clin Nutr 81, 1206S-1212S.

38. Ramakrishnan U, Grant F, Goldenberg T, et al. (2012) Effect of women's nutrition before and during early pregnancy on maternal and infant outcomes: a systematic review. Paediatr Perinat Epidemiol 26, Suppl. 1, 285-301.

39. Hann CS, Rock CL, King I, et al. (2001) Validation of the healthy eating index with use of plasma biomarkers in a clinical sample of women. Am J Clin Nutr 74, 479-486.

40. Locasale JW (2013) Serine, glycine and one-carbon units: cancer metabolism in full circle. Nat Rev Cancer $\mathbf{1 3}$ 572-583.

41. Fenech $M$ (2001) The role of folic acid and vitamin $B_{12}$ in genomic stability of human cells. Mutation Res 475, 57-67.

42. Marques AH, O'Connor TG, Roth C, et al. (2013) The influence of maternal prenatal and early childhood nutrition and maternal prenatal stress on offspring immune system development and neurodevelopmental disorders. Front Neurosci 7, 120.

43. Palmer AC (2011) Nutritionally mediated programming of the developing immune system. Adv Nutr 2, 377-395.

44. Roman E, Lightfoot T, Smith AG, et al. (2013) Childhood acute lymphoblastic leukaemia and birthweight: insights from a pooled analysis of case-control data from Germany, the United Kingdom and the United States. Eur J Cancer 49 1437-1447.

45. O'Neill KA, Bunch KJ, Vincent TJ, et al. (2012) Immunophenotype and cytogenetic characteristics in the relationship between birth weight and childhood leukemia. Pediatr Blood Cancer 58, 7-11.

46. Sprehe MR, Barahmani N, Cao Y, et al. (2010) Comparison of birth weight corrected for gestational age and birth weight alone in prediction of development of childhood leukemia and central nervous system tumors. Pediatr Blood Cancer $\mathbf{5 4}$, 242-249.

47. Oksuzyan S, Crespi CM, Cockburn M, et al. (2012) Birth weight and other perinatal characteristics and childhood leukemia in California. Cancer Epidemiology 36, e359-e365.

48. Hjalgrim LL, Westergaard T, Rostgaard K, et al. (2003) Birth weight as a risk factor for childhood leukemia: a metaanalysis of 18 epidemiologic studies. Am J Epidemiol 158, 724-735.

49. Caughey RW \& Michels KB (2009) Birth weight and childhood leukemia: a meta-analysis and review of the current evidence. Int J Cancer 124, 2658-2670.

50. Milne E, Greenop KR, Metayer C, et al. (2013) Fetal growth and childhood acute lymphoblastic leukemia: findings from the Childhood Leukemia International Consortium. Int J Cancer 133, 2968-2979.

51. Barker DJ, Lampl M, Roseboom T, et al. (2012) Resource allocation in utero and health in later life. Placenta 33, Suppl. 2, e30-e34

52. Voldner N, Froslie KF, Bo K, et al. (2008) Modifiable determinants of fetal macrosomia: role of lifestyle-related factors. Acta Obstet Gynecol Scand 87, 423-429.

53. Clausen T, Burski TK, Oyen N, et al. (2005) Maternal anthropometric and metabolic factors in the first half of pregnancy and risk of neonatal macrosomia in term pregnancies. A prospective study. Eur J Endocrinol 153, 887-894.

54. McGowan CA \& McAuliffe FM (2010) The influence of maternal glycaemia and dietary glycaemic index on pregnancy outcome in healthy mothers. Br J Nutr 104, $153-159$.
55. Lewis SJ (2014) Commentary: one-carbon metabolism has major implications for fetal growth and development beyond neural tube defects. Int $J$ Epidemiol 43 , 1498-1499.

56. Kalhan SC \& Marczewski SE (2012) Methionine, homocysteine, one carbon metabolism and fetal growth. Rev Endocr Metab Disord 13, 109-119.

57. Rush EC, Katre P \& Yajnik CS (2014) Vitamin $B_{12}$ : one carbon metabolism, fetal growth and programming for chronic disease. Eur J Clin Nutr 68, 2-7.

58. Relton CL, Pearce MS \& Parker L (2005) The influence of erythrocyte folate and serum vitamin $B_{12}$ status on birth weight. BrJ Nutr 93, 593-599.

59. Greaves MF \& Wiemels J (2003) Origins of chromosome translocations in childhood leukaemia. Nat Rev Cancer $\mathbf{3}$. 639-649.

60. Wiemels JL, Cazzaniga G, Daniotti M, et al. (1999) Prenatal origin of acute lymphoblastic leukaemia in children. Lancet 354, 1499-1503.

61. Guenther PM, Kirkpatrick SI, Reedy J, et al. (2014) The Healthy Eating Index-2010 is a valid and reliable measure of diet quality according to the 2010 Dietary Guidelines for Americans. J Nutr 144, 399-407.

62. Hiza HA, Casavale KO, Guenther PM, et al. (2013) Diet quality of Americans differs by age, sex, race/ethnicity, income, and education level. J Acad Nutr Diet 113, 297-306.

63. Kant AK \& Graubard BI (2007) Secular trends in the association of socio-economic position with self-reported dietary attributes and biomarkers in the US population: National Health and Nutrition Examination Survey (NHANES) 1971-1975 to NHANES 1999-2002. Public Health Nutr 10, $158-167$.

64. Hoerr SL, Tsuei E, Liu Y, et al. (2008) Diet quality varies by race/ethnicity of head start mothers. J Am Diet Assoc 108, 651-659.

65. Neuhouser ML, Thompson B, Coronado GD, et al. (2004) Higher fat intake and lower fruit and vegetables intakes are associated with greater acculturation among Mexicans living in Washington State. J Am Diet Assoc 104, 51-57.

66. Guendelman S \& Abrams B (1995) Dietary intake among Mexican-American women: generational differences and a comparison with white non-Hispanic women. Am J Public Health 85, 20-25.

67. Ayala GX, Baquero B \& Klinger S (2008) A systematic review of the relationship between acculturation and diet among Latinos in the United States: implications for future research. J Am Diet Assoc 108, 1330-1344.

68. Batis C, Hernandez-Barrera L, Barquera S, et al. (2011) Food acculturation drives dietary differences among Mexicans, Mexican Americans, and Non-Hispanic Whites. J Nutr 141, 1898-1906.

69. Byers T (2001) Food frequency dietary assessment: how bad is good enough? Am J Epidemiol 154, 1087-1088.

70. Freedman LS, Schatzkin A, Midthune D, et al. (2011) Dealing with dietary measurement error in nutritional cohort studies. J Natl Cancer Inst 103, 1086-1092.

71. Drews CD, Kraus JF \& Greenland S (1990) Recall bias in a case-control study of sudden infant death syndrome. Int $J$ Epidemiol 19, 405-411.

72. Verkerk PH, Buitendijk SE \& Verloove-Vanhorick SP (1994) Differential misclassification of alcohol and cigarette consumption by pregnancy outcome. Int J Epidemiol $\mathbf{2 3}$, $1218-1225$

73. Delgado-Rodriguez M, Gomez-Olmedo M, Bueno-Cavanillas A, et al. (1995) Recall bias in a case-control study of low birth weight. J Clin Epidemiol 48, 1133-1140. 
74. Mackenzie SG \& Lippman A (1989) An investigation of report bias in a case-control study of pregnancy outcome. Am J Epidemiol 129, 65-75.

75. Tilley BC, Barnes AB, Bergstralh E, et al. (1985) A comparison of pregnancy history recall and medical records. Implications for retrospective studies. Am J Epidemiol 121, 269-281.

76. Feldman Y, Koren G, Mattice K, et al. (1989) Determinants of recall and recall bias in studying drug and chemical exposure in pregnancy. Teratology $\mathbf{4 0}, 37-45$.
77. Zierler S \& Rothman KJ (1985) Congenital heart disease in relation to maternal use of Bendectin and other drugs in early pregnancy. $N$ Engl J Med 313, 347-352.

78. Klemetti A \& Saxen L (1967) Prospective versus retrospective approach in the search for environmental causes of malformations. Am J Public Health Nations Health 57, 2071-2075.

79. Infante-Rivard C \& Jacques L (2000) Empirical study of parental recall bias. Am J Epidemiol 152, 480-486. 